\title{
A REGULAÇÃO DOS LITÍGIOS COLETIVOS SOBRE A POSSE DE IMÓVEIS URBANOS NO CPC/15: AVANÇOS E LIMITES
}

\author{
Antônio Carlos Apolinário de Souza Cardoso ${ }^{1}$ \\ Roberto Apolinário de Souza Cardoso ${ }^{2}$
}

\section{RESUMO}

O presente artigo analisa em que medida a atual regulação do artigo 565 do CPC/15 avança na tutela da posse urbana. Para tanto os litígios sobre a posse são contextualizados com a questão da urbanização e da informalidade da moradia no Brasil, discutindo ainda a influência da formação da cidadania no Brasil neste processo, a partir das considerações de Holston (2013), e a influência do direito brasileiro na produção do espaço urbano. Este estudo busca acrescer ao debate processual questões de natureza social e econômica, sem as quais a natureza complexa dos litígios possessórios coletivos urbanos não pode ser compreendida.

Palavras-chave: litígios coletivos sobre a posse, ocupação, cidadania, direito à moradia, segurança jurídica da posse

\section{THE REGULATION OF COLLECTIVE DISPUTES ON URBAN PROPERTY IN CPC / 15: ADVANCES AND LIMITS}

\begin{abstract}
This article analyzes to what extent the current regulation of article 565 of CPC / 15 advances in the protection of urban possession. To this end, litigation over tenure is contextualized with the issue of urbanization and housing informality, discussing the influence of the formation of citizenship in Brazil in this process, based on the considerations of Holston (2013), and the influence of law in the production of urban space. This study seeks to add to the procedural debate issues of a social and economic nature, without which the complex nature of urban collective possessory litigation can not be understood.
\end{abstract}

Keywords: collective litigation on tenure, occupation, citizenship, right to housing, legal security of tenure

\section{INTRODUÇÃO}

A crise urbana brasileira tem como um dos principais desafios pendentes de

\footnotetext{
${ }^{1}$ Mestrando pela Universidade Federal do Pará, na área Direitos Humanos, linha de pesquisa Direitos Humanos e Meio Ambiente, sub-linha Direito Urbanístico. Graduado em Direito pelo Centro Universitário do Estado do Pará (2010). Atualmente é advogado - Pinheiro e Apolinário Advogados e consultor jurídico em Direito Registral, Imobiliário e Sucessório. Tem experiência na área de Direito, com ênfase em Direito Notarial e Registral e Direito Civil. Especialista em Direito Notarial e Registral, Direito Administrativo, Direito Tributário e Direito Público.

${ }^{2}$ Possui graduação em Direito pelo Centro Universitário do Estado do Pará (2011). Tem experiência na área de Direito do Trabalho, Direito Civil Empresarial, Direito Tributario e em Direito Agrário. Formado no LL.m em Direito Empresarial pela Fundação Getúlio Vargas Rio de Janeiro.
} 
enfrentamento o adequado tratamento jurídico das ocupações promovidas por famílias desalojadas, os sem teto. São eles pessoas expulsas do campo ou despejadas dos centros urbanos pela ausência de condições de permanecer na cidade (DAVIS, 2006).

O problema da precariedade urbana integra um dos maiores desafios posto à humanidade neste século, problema que se concentra e agrava nos países da periferia do capitalismo (DIAS, 2014, p. 36).

No tocante à realidade brasileira, importa destacar o impacto decorrente da construção da cidadania no Brasil, caracterizada por um sistema eleitoral restrito às camadas mais abastadas e pela reprodução das desigualdades sociais na distribuição de direitos e deveres (HOLSTON, 2013). Este cenário, elitista e antidemocrático, contribui para o crescimento do problema habitacional brasileiro, mais precisamente, levou a construção de uma legislação centrada no instituto da propriedade e excessivamente formalista, que condenou os mais pobres à informalidade (FERNANDES, 2010).

Entre as consequências sociais do déficit jurídico experimentado pelas classes populares, destacamos a insegurança jurídica da posse, em especial, seus reflexos nos conflitos sobre as ocupações em espaços urbanos.

A tutela da posse, em que pese suas implicações sociais, ambientais e econômicas, é regida, predominantemente, pelo direito civil; daí a inspiração individualista do regramento processual do tema, centrado na solução de conflitos individuais, e silente quanto aos conflitos coletivos sobre a posse, reforçando o desnivelamento jurídico entre os agentes em conflito na produção do espaço urbano.

Diante da constatação da omissão procedimental sobre os conflitos possessórios coletivos, o Código de Processo Civil de 2015 trouxe em seu artigo 565 o regramento específico para os conflitos coletivos sobre a posse.

O dispositivo possui aspectos promissores, como a necessidade de audiência de mediação em casos de posse superior ao ano e dia, além de contar com a previsão de intimação dos órgãos responsáveis pela política agrária ou urbana ( $\$ 4^{\circ}$ do art. 565 do CPC/15), entre outros pontos a serem destacados adiante a partir da análise da legislação, da consulta à doutrina e da leitura das decisões judiciais. 
O objetivo geral deste estudo é averiguar em que medida o artigo 565 do CPC/15 reduz o histórico déficit jurídico suportado pelos excluídos nas cidades. Os objetivos específico são:

a) apresentar a tutela legislativa dos conflitos coletivos sobre a posse, sob a luz do atual artigo 565 do $\mathrm{CPC} / 15$; b) demonstrar o déficit jurídico e político das populações pobres brasileiras em questões relativas ao acesso à terra urbana.

A hipótese levantada é a de que, embora o artigo 565 do CPC/15 traga inovações positivas ao direito brasileiro, aperfeiçoando o aspecto procedimental de uma espécie de litígio de amplo interesse social, suas alterações não são suficientes para sanar o problema da instabilidade da posse dos moradores de espaços informais.

Este estudo será conduzido da seguinte maneira: primeiro, será abordada a tutela dos litígios coletivos sobre a posse (seção 2), seu tratamento legislativo atual, bem como a relação com a disciplina civilista e a inovação proporcionada pelo art. 565 do CPC/15; após, passaremos à análise do problema habitacional nas cidades brasileiras, com enfoque em suas razões econômicas e políticas (seção 3); na seção 4, apontaremos a disputa pela produção do espaço urbano, utilizaremos do combate ao "analfabetismo urbano" (MARICATO, 2002) demonstrando o desequilíbrio entre os interesses em conflito (capital imobiliário vs setores populares); por fim, em sede de considerações finais, destacaremos a evolução no tratamento da matéria, indicando, contudo, seus evidentes limites ante o manifesto desnivelamento entre os interesses opostos.

\section{TUTELA DOS LITÍGIOS COLETIVOS PELA POSSE}

A tutela processual da posse se dá pelas ações possessórias, cuja origem remonta ao direito romano (MEDINA, 2009 p. 252) e sua regulação se encontra nos artigos 554 à 568 do CPC/15. -São fundadas no fato jurídico possell (MARINONI e MITIDIERO, 2012, p. 869) daí a fungibilidade ${ }^{3}$ entre suas espécies: reintegração de posse, manutenção da posse e interdito proibitório. Tratam-se, portanto, de institutos intrinsecamente ligados ao direito

\footnotetext{
${ }^{3}$ Neste sentido, Marinoni e Mitidiero (2012, p. 862): - Semelhante regra quer dizer que o juiz pode conceder a tutela possessória adequada, de acordo com o que restar provado no caso concreto, independentemente da espécie da ação possessória propostall. Está regra está expressamente consagrada no art. 554 do CPC/15.
} 
privado. O conceito de posse é extraído do art. $1.196 \mathrm{CC} / 02$ : "considera-se possuidor todo aquele que tem de fato o exercício, pleno ou não, de algum dos poderes inerentes da propriedade", portanto, posse é fato, aparência de direito -uma situação de fato, em que uma pessoa, que pode ou não ser a proprietária, exerce sobre uma coisa atos e poderes ostensivos, conservando-a e defendendo-all (PEREIRA, 2004, p. 14).

Prevaleceu no direito brasileiro a teoria objetiva da posse ${ }^{4}$, criticada por -subordinar a posse à propriedade, extirpando a sua autonomia, por reduzir a posse a um direito ínfimo, como mera exteriorização do direito de propriedade, ou seja, um complemento indispensável à sua tutelall (FARIAS e ROSENVALD, 2012, p. 65). Portanto, a concepção predominante sobre a posse no direito brasileiro é reduzida e -delineada de forma individualista e patrimonialistall, o que justifica a crítica de que -proteger a posse como forma de zelar pela propriedade não passa de uma forma de amesquinhar a posse e relegar o seu aspecto social (FARIAS e ROSENVALD, 2012, p. 73).

Ao direito processual "cabe a realização dos projetos do direito material, em uma relação de complementariedade" (DIDIER, 2016, P. 46), o que denota a forte influência de uma concepção da posse demasiadamente individualista ${ }^{5}$ na conformação das regras processuais voltadas à sua tutela.

Por outro lado, o direito brasileiro deve adaptar-se à constitucionalização do direito à moradia (art. $6^{\circ} \mathrm{CF}$ ), à função social da propriedade (art. $\left.5^{\circ}, \mathrm{XXIII}, \mathrm{CF}\right)$, à função social da propriedade urbana (art. 182, CF) e à função social da propriedade rural (art. $186 \mathrm{CF}$ ), posto que a constitucionalização do direito civil constitui uma realidade contemporânea, como ressalta Perlingiere (2007, p. 6):

O Código Civil certamente perdeu a centralidade de outrora. O papel unificador do sistema, tanto nos seus aspectos mais tradicionalmente civilísticos quanto naqueles de relevância publicista, é desempenhado de maneira cada vez mais

\footnotetext{
${ }^{4}$ Interessa transcrevermos a sucinta distinção da teoria objetiva e subjetiva feita por Chaves e Rosenvald, adotando a figura da detenção como fator distintivo (2012, p. 65): "SAVIGNY e IHERING concebem suas teorias com base em um ponto de partida comum: a detenção. Todavia, visceral é compreender que a teoria de IHERING é tida por objetiva pelo fato de explicar que a distinção entre possuidores e detentores não é traduzia à luz do elemento anímico da vontade de possuir, e sim por uma prévia conformação do ordenamento objetivo, que cuidará de explicitar as hipóteses em que certas pessoas não alcançarão a tutela possessória por expressa opção de política legislativa, em razão da forma pela qual ingressaram na coisa".

${ }^{5}$ Tendo-se em vista que Ihering, autor da teoria objetiva da posse, viveu e escreveu sua obra ao longo do século XIX, sendo fortemente influenciado pelo liberalismo clássico.
} 
incisiva pelo Texto Constitucional.

Em atenção às modificações ocorridas no direito brasileiro, notadamente as influências do direito constitucional, o legislador processual civil inovou o tratamento do tema da posse, com a edição do art. 565 do Código de Processo Civil vigente, buscando adequar o regramento processual à complexidade da sociedade atual. Nesse sentido, vejamos o que dispõe o CPC:

Art. 565. No litígio coletivo pela posse de imóvel, quando o esbulho ou a turbação afirmado na petição inicial houver ocorrido há mais de ano e dia, o juiz, antes de apreciar o pedido de concessão da medida liminar, deverá designar audiência de mediação, a realizar-se em até 30 (trinta) dias, que observará o disposto nos $\S \S 2^{\circ}$ e $4^{\circ}$.

$\S 1^{\circ}$ Concedida a liminar, se essa não for executada no prazo de 1 (um) ano, a contar da data de distribuição, caberá ao juiz designar audiência de mediação, nos termos $\operatorname{dos} \S \S 2^{\circ}$ a $4^{\circ}$ deste artigo.

$\S-2^{\circ}$ O Ministério Público será intimado para comparecer à audiência, e a Defensoria Pública será intimada sempre que houver parte beneficiária de gratuidade da justiça.

$\S 3^{\circ} \mathrm{O}$ juiz poderá comparecer à área objeto do litígio quando sua presença se fizer necessária à efetivação da tutela jurisdicional.

$\S 4^{\circ}$ Os órgãos responsáveis pela política agrária e pela política urbana da União, de Estado ou do Distrito Federal e de Município onde se situe a área objeto do litígio poderão ser intimados para a audiência, a fim de se manifestarem sobre seu interesse no processo e sobre a existência de possibilidade de solução para o conflito possessório.

$\S 5^{\circ}$ Aplica-se o disposto neste artigo ao litígio sobre propriedade de imóvel.

\section{$1.1 \mathrm{O}$ artigo 565 do CPC/15 e a mediação em conflitos fundiários coletivos}

É certo que a iniciativa que levou à adição do art. 565 no CPC/15 apresenta aspectos positivos, dignos de nota.

Primeiramente, o Código de Processo Civil, ao trazer dispositivo específico para litígios fundiários coletivos, apresenta inegável avanço ante a omissão legislativa pregressa. Relações como estas, coletivas e complexas, distanciam-se dos conflitos individuais, os quais têm como origem, em geral, demandas decorrentes de violações de direitos obrigacionais - produzindo efeitos materiais restritos aos sujeitos litigantes.

Tal conclusão se deve ao fato de que, ao invés do conflito entre dois sujeitos, cujos interesses podem ser resolvidos pelas regras clássicas civilistas, os litígios coletivos sobre a posse de imóveis são casos judiciais difíceis, em que não cabe o método da subsunção e onde não há uma resposta a priori (ABREU, 2011, p. 409), pois envolvem interesses de um 
número vasto de sujeitos que, embora vivam em situação informal ${ }^{6}$, possuem direito à moradia (art. $6^{\circ} \mathrm{CF}$ ), portanto, exigem tais casos, além das regras civilistas, a valoração do cumprimento da função social da propriedade urbana (art. $182 \mathrm{CF}$ ) e rural (art. 186 CF).

Ante à complexidade dos litígios coletivos sobre a posse, a previsão de realização de uma audiência de mediação, antes da concessão da medida liminar de reintegração de posse, constitui medida salutar, pois, ao menos, evita decisões açodadas que impedem a mobilização dos interessados e, também, impõe um período mínimo de reflexão ao juízo, permitindo a este maior ponderação sobre situações, por vezes, consolidadas há anos.

Outro ponto digno de nota foram os parágrafos $2^{\circ}$ e $4^{\circ}$ do art. 565 do CPC/15, os quais trouxeram a necessidade de intimação do Ministério Público para comparecer à audiência de mediação, e havendo parte beneficiária de gratuidade da justiça, a Defensoria Pública $\left(\$ 2^{\circ}\right)$; assim como, a abertura do procedimento à participação dos órgãos responsáveis pela política agrária e pela política urbana da União, de Estado ou do Distrito Federal e de Município onde se situe a área objeto do litígio.

Ainda sobre a possibilidade de abertura da relação processual a outros agentes, importa recordar que a intervenção do amicus curiae, propiciada pelo art. $138 \mathrm{CPC} / 15$, permite a intervenção de terceiros interessados para auxiliar o juízo na construção dos atos decisórios, levando ao seu conhecimento aspectos importantes da realidade social e urbana submetida à sua apreciação.

Os parágrafos $3^{\circ}$ e $5^{\circ}$ do art. 565 do $\mathrm{CPC} / 15$, também configuram alterações positivas. O parágrafo $3^{\circ}$, por reforçar a possibilidade de o juiz dirigir-se ao local do conflito, estimulando o juízo adotar uma conduta ativa que permite maior proximidade com a questão a ser decidida, em especial, o aspecto humano envolvido (famílias, crianças e idosos sujeitos ao despejo). E o parágrafo $5^{\circ}$, ao estender o rito especial dos litígios de posse coletivos às demandas decorrentes do direito de propriedade, como as ações reivindicatórias e os pedidos de imissão na posse nas demais ações petitórias ${ }^{7}$.

Por fim, destacamos a previsão da realização de mediação em litígios fundiários coletivos. A mediação é "uma mecanismo afeito à justiça consensual” (TARTUCE, 2015,

\footnotetext{
${ }^{6}$ Excluídos das relações jurídicas formais, sem contar com registros e menção em cadastros administrativos.

${ }^{7}$ Ações petitórias são relações processuais cujos efeitos se assemelham àqueles do rito especial possessório
} 
p. 176), e representa um dos métodos de solução consensual do conflito, forma de resolução a ser estimulada pelo Estado (art. $3^{\circ}, \S \S 2^{\circ}$ e $3^{\circ} \mathrm{CPC} / 15$ ).

Preceitua o Código de Processo Civil que o mediador -[...] auxiliará aos interessados a compreender as questões e os interesses em conflito, de modo que eles possam, pelo restabelecimento da comunicação, identificar [...] soluções consensuais\| (art. $\left.165, \S 3^{\circ}, \mathrm{CPC} / 15\right)$.

Como já afirmado, entendemos que o art. 565 do CPC/15 configura uma inovação salutar dentro de nosso sistema processual, todavia, as disposições trazidas pelo novo código de processo civil, por si só, são incapazes de sanar problema tão complexo quanto o da insegurança da posse dos moradores de espaços urbanos informais, cujas raízes, longe de e limitarem a aspectos jurídicos, derivam de questões econômicas, sociais e históricas (HOLSTON, 2013). Neste sentido, Explica Fernandes (2007, p. 20):

\begin{abstract}
Em especial, o papel da ordem jurídica na produção da informalidade urbana precisa ser mais bem-compreendido. Por um lado, a definição doutrinaria e a interpretação jurisprudencial dominantes do direito de propriedade imobiliária de maneira individualista, sem preocupação com a materialização do principio constitucional da função social da propriedade, tem permitido que o padrão do processo de crescimento urbano seja essencialmente especulativo, determinando os sistemas combinados de segregação socioespacial e segregação socioambiental. Por outro lado, tanto a ausência de leis urbanísticas municipais, quanto a aprovação pelos municípios de uma legislação urbanística elitista, baseada em critérios técnicos irrealistas e sem considerar os impactos socioeconômicos das normas urbanísticas e das regras de construção, também tem tido um papel fundamental na determinação dos preços da terra urbana, bem como na dinâmica segregadora do mercado imobiliário.
\end{abstract}

Por isso, cientes da discrepância jurídica, econômica e política dos titulares dos interesses representados em litígios coletivos pela posse urbana (famílias desabrigadas vs grandes especuladores e/ou Poder Público), entendemos que a mediação em conflitos de posse coletivos terá reduzida aplicabilidade, servindo apenas, na maioria dos casos, como uma etapa prévia à decisão, em especial, por duas razões, a saber: a) o princípio da isonomia entre as partes na mediação (art. $2^{\circ}$, II, da Lei 13.140/15), assim descrito por Tartuce (2015, p. 212) como o dever de -proporcionar igualdade de oportunidades aos envolvidos para que eles tenham plenas condições de se manifestar durante todo o procedimentoll, constitui fator deindevido nivelamento (dever de tratar como iguais), haja vista a desigualdade entre os sujeitos; b) pelo caráter das pretensões levadas a juízo, em outras palavras, a dificuldade de conciliar interesses especulativos (dos especuladores 
imobiliários) com o direito à moradia dos mais pobres.

\section{CONSIDERAÇÕES SOBRE A URBANIZAÇÃO BRASILEIRA}

A urbanização brasileira, assim como nos demais países do terceiro mundo, é marcada pela exclusão. Com base em Davis (2006, p. 22), podemos elencar os seguintes fatores que impulsionam a urbanização na periferia do capitalismo: seca, inflação, aumento dos juros para os empréstimos aos produtores rurais, queda do preço das commodities, mecanização da agricultura e até conflitos armados estimulados pela desorganização econômica do ajuste estrutural imposto.

O processo de urbanização brasileiro deu-se praticamente na segunda metade do século XX (MARICATO, 2003, P. 151). Em um espaço de 50 anos, a distribuição da população brasileira se transformou de forma abrupta. Na década de 1960, a população urbana brasileira foi estimada em 32.004.817 e a rural em 38.987.526; apenas uma década depois, 1970, a população urbana salta para 52.904.744 e a rural para 41.603.839; em 1980 o fenômeno urbano explode, passando as cidades brasileiras à abrigarem 82.013.375 pessoas, enquanto o campo via sua população diminuir para 39.137.198; em 2010 a população urbana brasileira chegou ao surpreendente número de 160.925 .792 e o campo regrediu para 29.830.007, marca inferior a da década de 1960 (IBGE, 2010). Acerca da intensidade com que ocorreu a urbanização brasileira, pontua Rolnik (2006, p. 1): Em um dos movimentos socioterritoriais mais rápidos e intensos de que se tem notícia, a população brasileira passou de predominantemente rural para majoritariamente urbana em menos de $40 \operatorname{anos}(1940-1980)$.

Afirma Davis (2006, p. 22) que “a dinâmica da urbanização no Terceiro Mundo recapitula e confunde os precedentes da Europa e da América do Norte no século XIX e início do século XX”. As distintas realidades estampadas pelos países que protagonizaram a revolução industrial, como a Inglaterra vitoriana, e àquelas dos países em desenvolvimento evidenciam as profundas diferenças entre os processos de urbanização ocorridos e em andamento nestes países.

Enquanto no século XIX e em meados do século XX o êxodo rural nos países desenvolvidos foi acompanhado da expansão dos empregos industriais e de índices de crescimento da economia, na urbanização tardia, experimentada nos países em 
desenvolvimento, a ida às cidades se assemelha a uma fuga, à busca pela sobrevivência ante a ausência de condições de permanecer no campo, fenômeno independente do desenvolvimento econômico ou da oferta de empregos. Neste sentido, esclarece Davis (2006, p. 23):

Desde meados da década de 1980, as grandes cidades industriais do hemisfério sul - Bombaim, Joanesburgo, Buenos Aires, Belo Horizonte e São Paulo - sofreram todas o fechamento maciço das fábricas e a tendência à desindustrialização. Em outros lugares, a urbanização desligou-se mais radicalmente da industrialização e até do desenvolvimento propriamente dito, e, na África subsaariana, daquela suposta condição sine qua non da urbanização, o aumento da produtividade agrícola.

Por essas razões, adota-se a premissa levantada por Davis (2006) de que as elevadas taxas de crescimento da população urbana nos países em desenvolvimento se devem, sobretudo, à expansão da pobreza e da fome resultantes da adoção das políticas de austeridade e de desregulamentação agrícola preceituadas pelo Fundo Monetário Internacional (FMI) e pelo Banco Mundial. Assevera Davis (2006, p. 26) que a "superurbanização" é estimulada: "pela reprodução da pobreza, não pela oferta de empregos. Essa é apenas uma das várias descidas inesperadas para as quais a ordem mundial neoliberal vem direcionando o futuro".

Essa conclusão vai ao encontro das considerações de Maricato (2003, p. 162), que acresce à crítica de Davis (2006), as perversas consequências das diretrizes econômicas neoliberais sobre a frágil situação social e política brasileira:

A ideologia presente nestas mudanças pelo Consenso de Washington completou o trabalho de desarticular e desorganizar boa parte daquilo que não havia ainda adquirido escala universalizante na sociedade brasileira: emprego, previdência social, assistência à saúde, educação, moradia, transporte, saneamento.

Importante ressaltar, diante da lógica liberal prevalecente, que o aumento da população urbana veio acompanhado do crescimento das demandas por serviços essenciais como a melhoria do transporte urbano, construção de escolas e creches, acesso à água potável, serviços de saneamento básico; em resumo, criou um aumento da demanda pela expansão de um Estado Social, o qual sequer chegou a existir na realidade brasileira.

Ao descrever as consequências do acelerado crescimento urbano vivido na América Latina nas últimas décadas do século XX, explica Osório (2006, p. 19): 
O crescimento urbano incrementou a demanda habitacional, bem como a carência de serviços essenciais: o déficit nacional acumulado de moradia afeta, atualmente, um terço dos lates latino-americanos; ao menos 25 milhões de moradias não possuem água potável; e um terço do parque habitacional urbano não dispõe de sistema cloacal.

Como se as consequências do crescimento desenfreado das cidades no Brasil e no restante da América Latina, desacompanhado de crescimento das riquezas nacionais, não fosse suficientemente preocupante, a realidade destes países é caracterizada por um enorme déficit democrático cujas consequências se refletem na elaboração das políticas públicas e em sua produção legislativa. Sobre este ponto assevera Osório (2006, p. 20):

Do ponto de vista político a maioria dos países latino-americanos é rico em normas e procedimentos democráticos, e os presidentes são eleitos direta ou indiretamente pelos cidadãos. Trata-se, entretanto, de democracias formais, pois é perceptível a falta de representação política de setores marginalizados da sociedade no cenário eleitoral, e mesmo havendo pleitos para dirigentes, os legisladores continuam sendo escolhidos, muitas vezes, pelas oligarquias tradicionais dominantes. São traços herdados de uma tradição política autoritária, tais como clientelismo, paternalismo, patrimonialismo, personalismo e troca de favores, que continuam sendo fatores relevantes da política da região.

A perpetuação dos interesses dos setores dominantes da sociedade brasileira à frente da política produziu reflexos jurídicos. O descompasso entre as normas que regulam o acesso à terra urbana, como o direito civil e as normas administrativas de posturas municipais e sobre o direito de construir, refletem o distanciamento entre a realidade dos marginalizados e o dever ser preceituado pelo Direito brasileiro. Aponta Alfonsin (2007, p. 71-72):

A tensão legalidade/ilegalidade acompanha a formação do Estado e do território brasileiro, em especial das cidades. [...] O fato é que essa perversa combinação do Direito Civil com o Direito Urbanístico condena uma boa parte da população das cidades a uma condição de subcidadania, pois sua relação com a terra não é titulada e a ocupação está sempre desconforme com os preceitos urbanísticos. Derivou daí uma profunda desigualdade na distribuição dos investimentos públicos, que, historicamente, no Brasil, sempre ocorrem nas regiões já bem infra-estruturadas da cidade. Assim, a irregularidade jurídico-urbanística da ocupação serve como uma espécie de -escudol, para justificar o abandono dos territórios -fora-da-leill pelo Poder Público e a lei serve como instrumento de acumulação de riqueza e concentração da renda nas cidades, e, portanto, como fonte inequívoca de legitimação de uma ordem excludente e injusta.

No Brasil e em grande parte do mundo em desenvolvimento, as cidades têm sido tratadas como mercadorias, fontes de lucro ampliadas pela tradicional cumplicidade com os interesses especulativos, dado importante para compreender como o Brasil chegou ao topo do ranking internacional de valorização imobiliária, segundo Alfonsin e Fernandes (2014, p. 15). Os autores criticam esta forma mercadológica da cidade: 
Assim como em muitos outros países, no Brasil pós-industrial e globalizado, verifica-se a produção capitalista $d a$ própria cidade, tratada como mercadoria por diversos atores socioeconômicos e político-institucionais, e cada vez mais gerida como uma empresa. $\mathrm{O}$ aumento vertiginoso dos preços de propriedades e aluguéis tem feito com que valores individuais de troca prevaleçam ainda mais sobre quaisquer valores sociais de uso. $\mathrm{O}$ outro lado da moeda tem sido as remoções e despejos de dezenas de milhares de famílias; a periferização dos mais pobres; e a pressão sobre terras públicas de proteção ambiental e rurais, levando a uma profunda crise socioambiental.

Então, diante da combinação de fatores sociais, jurídicos e econômicos ${ }^{8}$ à população pobre a única opção de moradia permitida nas cidades foi a ocupação informal, em outras palavras, aos excluídos restaram as áreas periféricas, as áreas centrais não dotadas de infraestrutura urbanística e áreas não adequadas à ocupação (íngremes, risco de deslizamento e etc) e de preservação ambiental (FERNANDES, 2007, p. 21).

Um dos reflexos mais expressivos da exclusão urbanística é a favelização, fenômeno caracterizado pela ocupação de imóveis abandonados (públicos e privados) e espaços ambientais protegidos (MARICATO, 2010, p. 9).

Favelização significa um fato social ou fenômeno que se manifesta de modo particular a depender do local, sofrendo variações culturais e geográficas. Há favelas, por exemplo, no Rio de Janeiro com suas peculiaridades geográficas próprias, assim como existem favelas em Belém do Pará, Salvador, Belo Horizonte, Maputo (Moçambique), Kinshasa e Cochabamba (Bolívia), todas elas com suas particularidades, compartilhando, no entanto, precariedade, violência e servindo de abrigo aos excluídos da sociedade.

Diante destes fatos, não há como não conferir razão à conclusão Kovarick (1993) de que nas metrópoles brasileiras imperou o modelo da -lógica da desordeml, caracterizado pela desregulação sobre o uso do solo urbano, a insensibilidade política às demandas da classe trabalhista, exclusão dos pobres no planejamento urbano bem como a conivência com a atividade especulativa.

\footnotetext{
${ }^{8}$ Fernandes (2006, p. 50) elenca as seguintes causas, como aquelas determinantes para o crescimento da informalidade urbana: - As principais causas reconhecidas vão desde fatores globais e fatores macroeconômicos até variáveis locais, mas cinco causas principais merecem atenção especial, quais sejam: a falta de opções formais resultantes da natureza das políticas fundiárias, habitacionais, urbanas e fiscais dos governos; a dinâmica excludente dos mercados de terras formais, que não incluem os pobres; a longa tradição de manipulação política dos moradores de assentamentos informais mediante práticas renovadas de clientelismo político; os sistemas de planejamento urbano elitistas e tecnocráticos que são implantados pelas administrações locais, sem levar em conta as realidades socioeconômicas de acesso ao solo e produção da moradia, e nem a capacidade de ação das próprias administrações locais para garantir o cumprimento da legislação urbanística; e a natureza obsoleta dos sistemas jurídicos e procedimentos judiciais que ainda prevalecem na maioria dos países em desenvolvimento e em transição".
} 
No entanto, Kovarick (1993) reconheceu que a "desordem" urbana não derivava do acaso, da simples falta de planejamento, mas, como Davis (2006), enxerga no sistema de produção capitalista e suas consequências na economia e na produção do espaço urbano a razão por trás da crescente segregação urbana, por isso, concluiu Kovarick (1993, p. 54): “As coisas simples precisam constantemente ser ditas: é o capital - e não sua força de trabalho - que deteriora a vida metropolitana. Para o capital, a cidade e a classe trabalhadora interessam como fonte de lucro.” Neste sentido, se manifesta Maricato (2010, p.9):

Se considerarmos o número de favelas e o número de seus moradores que invadem terra para morar, podemos dizer que uma gigantesca invasão de terras urbanas é consentida pelo Estado, nos países não desenvolvidos, mesmo contrariando as leis urbanísticas ou de proteção ambiental. Essas invasões não são dirigidas por movimentos contestatários, mas pela falta de alternativas. Já que todos precisam de um lugar para morar e ninguém vive ou se reproduz sem um abrigo, esse consentimento à ocupação ilegal, não assumido oficialmente, funciona como uma válvula de escape para a flexibilização das regras. Mas esse consentimento e flexibilização se dão apenas em áreas não valorizadas pelo mercado imobiliário (acrescentamos: enquanto não valorizadas pelo mercado). $\mathrm{O}$ mercado mais do que a lei — norma jurídica — é que define onde os pobres podem morar ou invadir terras para morar. Há uma lógica que relaciona mercado e aplicação da lei.

Ninguém escolhe viver em situação irregular. Se for razoável considerar que a pobreza constitui "por si só, uma violação de vários direitos humanos fundamentais" (ROBINSON, 2006, p. 88-119), com maior razão podemos afirmar que a vida nas favelas e outros espaços precários concebem uma das mais evidentes formas de negação da dignidade humana.

A precariedade de condições de habitabilidade enfrentada pelos moradores de favelas, por exemplo, agrava a situação daqueles que já vulneráveis, economicamente, são expulsos para espaços desprovidos de infraestrutura básica, os quais, cada vez mais distantes dos locais de trabalho, carentes de espaços verdes, lazer, escolas, creches e unidades de saúde ${ }^{9}$, encontram-se em situação de hipervulnerabilidade; razões pelas quais, Kovarick (1993, p. 88) denominou as vítimas da segregação espacial de "pobres dentre os

\footnotetext{
${ }^{9}$ Sobre isso, Rolnik (2006, p. 200): - A presença desse vasto contingente de assentamentos inseridos de forma ambígua na cidade é uma das mais poderosas engrenagens da máquina de exclusão territorial que bloqueia o acesso dos mais pobres às oportunidades econômicas e de desenvolvimento humano que as cidades oferecem. Essa situação de exclusão é muito mais do que a expressão das desigualdades sociais e de renda: ela é agente de reprodução dessa desigualdade. Em uma cidade dividida entre a porção legal, rica e com infra-estrutura, e a ilegal, pobre e precária, a população que está em situação desfavorável acaba tendo muito pouco acesso a oportunidades de trabalho, cultura e lazer. Simetricamente, as oportunidades de crescimento circulam no meio daqueles que vivem melhor, pois a sobreposição das diversas dimensões da exclusão incidindo sobre a mesma população fazem com que a permeabilidade entre as duas partes seja muito pequena.
} 
pobres".

O viver em assentamentos precários carrega como característica a fragilidade jurídica e social, quer dizer: carência ou inexistência de serviços públicos, insegurança jurídica da posse, além de péssimas condições ambientais (por exemplo, saneamento débil ou inexistente), conjunto de omissões que levaram Maricato (2010, p. 10) a afirmar que "a exclusão é um todo", representada por um acúmulo de vulnerabilidades que atingem os mais carentes.

É justamente nessas áreas estranhas ao contrato social que se concentram os socialmente excluídos: desempregados, grande concentração da população negra, desproporcional taxa de mulheres chefes de família, menores índices de educação e alta taxa de mortalidade infantil (MARICATO, 2010, p. 10).

São espaços ocupados por minorias, pobres e marginalizados, locais onde o Estado é ausente, por isso são o destino mais comum de atividades poluidoras, tóxicas e ilegais, onde costuma prevalecer a "lei do mais forte" (DAVIS, 2006). Nestes lugares esquecidos, exceto nas campanhas eleitorais e nos diários policiais; onde o crime organizado e as milícias atuam-governam pelo terror. Vide os dados estarrecedores que integram o relatório final da CPI brasileira contra assassinato de jovens, que aponta estar em andamento verdadeiro "genocídio da população negra"

No entanto, mesmo diante de tantas privações e violências, os moradores de áreas precárias vivem ainda sob a constante tensão do despejo. Como mencionado acima, a insegurança jurídica da posse surge como uma das características da precariedade urbana. Neste sentido, asseveram Saule Júnior e Cardoso (2005, p. 10)

A respeito da violação da segurança da posse, Saule Jr (2005, p. 33) é assertivo ao considerar que a segurança de posse é uma proteção jurídica que

\footnotetext{
${ }^{10}$ O relatório final da CPI dos assassinatos contra jovens versa que: - O tema mais candente, que se relaciona ao racismo institucional bem como ao escopo desse relatório, se refere às altas taxas de homicídios dos jovens negros. Segundo os dados do Mapa da Violência, a taxa de homicídio entre adolescentes negros é quase quatro vezes maior do que entre os brancos (36,9 a cada 100 mil habitantes, contra 9,6). "O fato de ser homem multiplica o risco de ser vítima de homicídio em quase 12 vezesll, ressalta o relatório. [...] As mortes por assassinato da juventude negra estão diretamente relacionadas à ação ou omissão do Estado. De um lado, a proliferação do tráfico de drogas nas comunidades de baixa renda, sobretudo nas favelas, é resultado, em última análise, da falta de segurança pública e da ausência dos órgãos de Estado. Em um ambiente onde a omissão do Poder Público suscita o aparecimento de grupos organizados de traficantes, bem como de milícias, os índices de violência contra a juventude negra atingem o paroxismo".
} 
confere dignidade ao morador, em virtude de eliminar o temor das ameaças de despejo, conferindo planejamento familiar e investimentos na melhoria de sua habitação.

$\mathrm{O}$ direito à moradia, o qual pressupõe a estabilidade da posse ${ }^{11}$, integra o rol dos direitos fundamentais (art. $6^{\circ}$ Constituição Federal), assim como a função social da propriedade urbana também possui previsão constitucional (art. $182 \mathrm{CF}$ ), todavia, a hermenêutica jurídica dominante é fortemente influenciada por concepções liberais, em especial, a propriedade como riqueza circulável. Segundo Harvey (2014, p. 27):

Vivemos em uma época em que os ideais dos direitos humanos passaram para o primeiro plano tanto política quanto eticamente. Dedica-se muita energia política na construção, defesa e articulação de sua importância na construção de um mundo melhor. Na maior parte, os conceitos em vigência são individualistas e baseados na propriedade, e, como tais em nada contestam a lógica de mercado hegemônica liberal e neoliberal. Afinal, vivemos em um mundo do qual os direitos de propriedade privada e a taxa de lucro se sobrepõem a todas as outras noções de direitos em que se possa pensar.

A conformação de um sistema jurídico construído a partir da concepção liberal da propriedade leva à ineficácia de princípios como o da função social, socioambiental e urbana da propriedade, pois a visão da moradia como simples mercadoria segue apenas a lógica do lucro especulativo (FERNANDES, 2010, p. 179).

Embora a insegurança jurídica da posse seja uma característica da favelização, fenômeno global (DAVIS, 2006), no Brasil, a questão do acesso à propriedade fundiária, deve partir da compreensão do processo de construção da democracia brasileira, posto que suas "peculiaridades" históricas influenciaram significativamente a política legislativa, marcadamente discriminatória (HOLSTON, 2013).

A urbanização à brasileira é um dos reflexos do processo de constituição da cidadania no Brasil, uma cidadania "diferenciada" (HOLSTON, 2013, p. 120), cuja origem reside em uma série de exclusões políticas sociais e espaciais a incidir sobre os mais pobres.

Explica Holston (2013) que a cidadania brasileira é caracterizada pela previsão de

\footnotetext{
${ }^{11}$ Ver neste sentido o Comentário Geral no 4 do Comitê de Direitos Econômicos, Sociais e Culturais, de 12 de dezembro de 1991 e BRASIL. Secretaria de Direitos Humanos da Presidência da República. Por uma Cultura de Direitos Humanos: Direito à moradia adequada. Brasília: Coordenação Geral de Educação em SDH/PR, Direitos Humanos, Secretaria Nacional de Promoção e Defesa dos Direitos Humanos, 2013. Disponível em: 〈http://www.sdh.gov.br/assuntos/bibliotecavirtual/promocao-e-defesa/publicacoes-2013/pdfs/direito-amoradia-adequada>. Acesso: 02. mar. 2018
} 
acesso universalizante, mas tradicionalmente repleta de condicionantes de acesso (exigências de documentação, renda e alfabetização), requisitos de participação que inviabilizaram o direito ao voto dos mais humildes, sistema restritivo que resultou em uma legislação acentuadamente elitista e desigual na distribuição de direitos (HOLSTON, 2014, p. 258).

A exclusão sistemática das massas da participação no processo político tornou viável a construção de um sistema legal centrado na propriedade, repleto de garantias a serviço da circulação de riquezas; mas omisso quanto à garantia do direito à moradia, e inflexível diante da informalidade característica dos espaços periféricos. Para Holston (2013, p. 259):

A exclusão dos direitos políticos negava às massas a participação na elaboração da lei, sua exclusão da propriedade fundiária tornava a ilegalidade a norma de suas moradias, e sua incorporação no mercado de trabalho como, na prática, trabalhadores servis lhes negava a dignidade. Essa exclusões possibilitaram a construção e perpetuação de uma cidadania diferenciada.

As omissões do poder público, relativas à democratização do espaço urbano, impulsionam a extrema precariedade dos espaços informais, pois o déficit de representatividade de uma enorme parcela da população impediu os mais necessitados da participação dos processos de formulação das políticas relativas à produção do espaço urbano (alocação dos investimentos públicos, construção de obras e a forma prestação de serviços públicos).

Portanto, a "escolha" por viver em espaços precários, em verdade, é o reflexo da segregação espacial urbana, que é consequência direta do modelo de urbanização dotado, a serviço de interesses elitistas e do mercado imobiliário. Neste sentido, conclui Fernandes (2010, p. 179-180):

[...] também deve ser reconhecido que essa única opção existente, por mais que efetivamente envolva grande dinamismo e criatividade por parte dos moradores em assentamentos informais, não pode ser considerada uma opção adequada em termos ambientais, urbanísticos, sociais e jurídicos. Além de viver em condições de grande precariedade urbanística e ambiental, a enorme população dos assentamentos informais não tem segurança jurídica da posse, ficando à mercê de despejos e remoções, pressões de proprietários, políticos, bandidos, traficantes e especuladores. Sem terem sequer um endereço em muitos casos, são milhões de pessoas que não têm acesso aos benefícios da urbanização, ao crédito formal e às condições básicas de cidadania.

Por outro lado, importa ressaltar que viver em espaços precários constitui um ato de resistência por parte dos expulsos ou excluídos do mercado formal, pessoas que diante da 
necessidade de viver na cidade, não possuem alternativa senão a ocupação e a construção informal. Ou seja, a informalidade é também um ato de resistência, de insurgência diante da exclusão formal (HOLSTON, 2013). Neste sentido conclui Silva (2013): "entendo que favela é uma determinação subjetiva, isto é, um desejo dos pobres de permanecer na cidade, de construir estratégias cotidianas para uma vida melhor mesmo em situações de precariedade, violência e risco".

\section{ANALFABETISMO URBANO E DESEQUILÍBRIO DE FORÇAS NA CIDADE}

Para entender a dinâmica da produção do espaço urbano é necessário compreender as forças que o disputam, em outras palavras, entender que a cidade é moldada a partir da conjugação de interesses conflitantes. De um lado, a maioria de seus moradores, composta pelas camadas populares, interessadas na ampliação da infraestrutura de serviços públicos e no crescimento moderado do custo de vida urbano (valor do aluguel, preço do transporte e etc); de outro, as elites, devotadas à apropriação privada dos espaços dotados de potencial de valorização (áreas verdes, zonas litorâneas e etc) e a concentração dos investimentos públicos nas zonas centrais.

A assimilação dos interesses antagônicos na composição das cidades constitui condição para uma construção democrática da urbe, pois possibilita a conscientização e a mobilização social, o que favorece a organização em torno de estratégias de resistência às tentativas de apropriação dos espaços coletivos pelos setores dominantes.

Este processo de compreensão das dinâmicas sociais na conformação do espaço urbano, Ermínia Maricato (2002) denomina de "analfabetismo urbano"12, fenômeno a ser combatido segundo as palavras da autora:

Para erradicar o analfabetismo urbanístico seja na chamada sociedade civil, seja entre técnicos e administradores é preciso resgatar o tema do estreito círculo dos urbanistas e ampliar o vocabulário para além do hermético "urbanês". É preciso evidenciar, para as camadas populares, as estratégias das classes sociais na produção e ocupação do espaço, ou seja, nada aí é natural ou fruto do acaso. Junto aos técnicos (especialmente junto aos economistas) e políticos é preciso evidenciar o alto custo que decorre da irracionalidade na ocupação predatória e extensiva do solo urbano.

Como assinalado por Holston (2013) a criação e a perpetuação de uma "cidadania diferenciada" no Brasil, teve origem na consolidação de uma cidadania

12 Ver: MARICATO, Ermínia. Cidade é luta de classes. Youtube, 11 Jan, 2016. Disponível em < https://www.youtube.com/watch?v=9R4S6ZaDniU\&t=146s $>$. Acesso em: 23 out. 17. 
meramente formal, aparentemente inclusiva na previsão de acesso, mas demasiadamente restritiva quanto à distribuição dos direitos (HOLSTON, 2013, p. 258), fato que resultou na confecção de uma legislação voltada aos interesses dos mais abastados e insensível às demandas populares.

A desigualdade à brasileira possui particularidades que por si só escancaram o desnivelamento jurídico entre as forças sociais que disputam a apropriação dos espaços urbanos. No entanto, o conjunto de desvantagens que afeta os menos abastados não se limita às influências endógenas; pois o Brasil, país periférico do capitalismo global, não é invulnerável aos efeitos da globalização econômica e seus impactos sobre a política, pelo contrário, aqui as diretrizes mercadológicas têm recebido calorosa acolhida (MAGALHÃES, 2013).

Por essas razões, os problemas relativos ao acesso a terra e à moradia, na realidade brasileira, são tão urgentes; posto que no Brasil a desigualdade jurídica entre as camadas dominantes e os setores populares é gritante, o que deixa ainda mais vulnerável a situação dos moradores de espaços informais diante do avanço dos interesses capitalistas sobre a produção do espaço urbano.

Atento a esta realidade e à produção do espaço urbano como estratégia de competição no capitalismo global ${ }^{13}$, escreveu Kovarick $(1993$, p.92) sobre a forma como nosso sistema jurídico legitima a expulsão:

[...] o fato de ser favelado tem desqualificado o indivíduo da condição de habitante urbano, pois retira-lhe a possibilidade de exercício de uma defesa que se processa em torno da questão da moradia. Ocupante de terra alheia, o favelado passa a ser definido por sua situação de ilegalidade, e sobre ele desaba o império draconiano dos direitos fundamentais da sociedade, centrados na propriedade privada, cuja contrapartida necessária é a anulação de suas prerrogativas enquanto

\footnotetext{
${ }^{13}$ Explica Kovarick (1993) como o espaço urbano foi concebido de modo a favorecer as pretensões capitalistas, posto que além de oferecer mão-de-obra jovem abundante e disponível ao mercado (reduzindo o poder de pressão da classe trabalhadora), a instabilidade da posse permite ainda que o trabalhador possa acompanhar a demanda da mão de obra por meio da expulsão, "mão-de-obra flutuante": "[...] parte dos trabalhadores da capital não permanecem no emprego por período superior a um ano. Tal fenômeno pode ser extremamente útil para determinadas atividades econômicas. Dentro da cidade, a possibilidade de maior locomoção residencial serviria para seguir os caminhos intinerantes da construção civil. No âmbito mais geral da economia, serviria como mãode-obra flutuante, constante e periodicamente atraída e expulsa pelos surtos tanto urbanos como agrários, podendo se deslocar mais facilmente em função das necessidades do processo de acumulação, pois está de certe forma desatada de um local de residência. Dessa forma, enquanto caso exemplar de mão-de-obra que se apresenta como "pau pra toda obra", o favelado pode facilmente preencher as necessidades mais imediatas da engrenagem produtiva que na cidade e no campo, frequentemente, precisa mobilizar de maneira rápida contingentes ponderáveis de força de trabalho não qualificada" (KOVARICK, 1993, p. 90)
} 
morador. Assim, nem nesse aspecto mínimo o favelado tem aparecido enquanto cidadão urbano, surgindo aos olhos da sociedade como um usurpador que pode ser destituído sem a possibilidade de defesa, pois contra ele paira o reino da legalidade em que se assenta o direito de expulsá-lo. (Grifos nossos)

Tais constatações explicam a lógica de forças por trás das ordens de desocupação de espaços abandonados promovidos nas ações de reintegração de posse, baseadas unicamente na defesa da propriedade formal - a titularidade constante em acervos públicos - e omissas quanto aos deveres condicionantes da propriedade, decorrentes de sua funcionalização (art. $5^{\circ}$, XXIII CF; art. 170, III, CF; art. 182 CF; art. 186 CF).

É certo ressaltar, como o fez Abreu (2011, p. 399), que -a justiça brasileira é um dos agentes mais acionados para promover, com aparência de legitimidade jurídica, os despejos forçados de assentamentos informais - e costuma aceitar o encargoll. O Poder Judiciário brasileiro, agindo dessa maneira, tem ratificado a predominância da propriedade sobre a moradia (ABREU, 2011, p. 404-405) e, por conseguinte, posicionando-se na disputa pela cidade, constatação que escancara a gravidade e a profundidade das lutas sociais pelo direito à moradia em nossas cidades, e denota o desnível jurídico dos interesses contrapostos, pois os direitos dos mais pobres além de carecerem de tratamento legislativo adequado são prejudicados por uma hermenêutica jurídica excessivamente privatista e inclinada aos interesses elitistas, preferência que se exterioriza nas ordens de desocupação ${ }^{14}$.

\section{CONSIDERAÇÕES FINAIS}

O problema urbano no Brasil é resultado da exclusão do processo democrático das massas, "cidadania diferenciada" (HOLSTON, 2013), e ampliada pelos reflexos da expansão neoliberal.

Daí afirmarmos que o viver em situação informal não constitui uma escolha ou, tampouco, atividade furtiva. Morar em situação de vulnerabilidade é resultado de um processo histórico, cujos pilares se fundamentam na perpetuação e ampliação das desigualdades sociais e econômicas.

Necessário perceber que a construção da cidadania brasileira não foi um processo

\footnotetext{
${ }^{14}$ Ver a nota de rodapé 6, acima, onde Abreu (2011, p. 400) elenca casos ilustrativos de despejo promovido por ordens judiciais.
}

Revista de Processo, Jurisdição e Efetividade da Justiça | e-ISSN: 2525-9814 | Salvador | v. 4 | n. 1 | p. 163 
decorrente da apatia social, o "mito da sociedade amorfa" desmascarado por Kovarick (1993, p.25-31), a bem da verdade, resultou de um processo político engendrado para excluir e, com isso, explorar os mais humildes de acordo com as conveniências das classes dominantes, sendo a espoliação urbana (KOVARICK, 1993) o mais significativo e perverso reflexo da

-cidadania diferenciadal (HOLSTON, 2013).

Esta espoliação se perpetua por duas razões, em especial, a saber: a) a insegurança da posse que -legitimal a contínua expulsão por ordens judiciais, o despejo -jurídicoll; b) aexpulsão indireta, pelo endividamento, que resulta da compressão salarial e do aumento do preço da terra (KOVARICK, 1993, p. 83), o despejo-econômicoll.

A consciência de que a restrição aos direitos políticos, imposta à maioria, e a crescente influência do capital imobiliário sobre a política serve para aclarar os porquês das escolhas políticas que serviram à segregação urbana. Em outras palavras, compreender as razões para a concentração da infraestrutura urbana em áreas alvo de especulação e o desenvolvimento de políticas que promovem a gentrificação ${ }^{15}$, são fatos que auxiliam na demonstram os estreitos laços entre o público e privado (capital especulativo) que garantem o predomínio da produção do espaço urbano como mercadoria.

Esse cenário espoliativo contou, e conta, com a colaboração de um de um sistema jurídico ainda dominado por concepções liberais, como a posse acessória à propriedade ${ }^{16}$ (art. $1.196 \mathrm{CC}$ ) e o emprego de instrumentos processuais ordinários (baseados em uma estrutura processual que se fundamenta em conflitos bilaterais), assim como, interpretações dogmáticas que abstraem o fundamento social dos conflitos judiciais, -coisificando-osl (Warat, 2002, p. 57-99; Faria, 1997, p. 100-102; Streck, 2003, p. 77-87, apud, ABREU,

\footnotetext{
${ }^{15}$ Sobre gentrificação a didática explicação de Mendes (2011, p. 479) - A gentrificação trata-se de uma recentralização urbana e social seletiva, alimentada por novas procuras, promotora de uma crescente revalorização e reutilização física e social dos bairros de centro histórico, indiciando, por conseguinte, novos processos de recomposição da sua textura socioespacial. Essa tendência encontra-se associada à recomposição do sistema produtivo, cuja evolução se pauta por uma crescente terciarização e pela emergência de um novo modelo de acumulação capitalista mais flexível, que reconhece no (re)investimento no centro histórico - de capital imobiliário, e na sua circulação "uma mais-valia".

${ }_{16}$ Neste sentido, se posicionam Mastrodi e Alves (2017, p. 10): “Sem segurança jurídica, os moradores possuidores não têm proteção legal para viver com dignidade e paz, já que sua posse é compreendida como um fato sempre precário e, muitas vezes, contrário ao direito de propriedade. Estes moradores tendem a viver com o temor de ameaças de despejo, o que compromete sua qualidade de vida, já que a insegurança dificulta circunstâncias normais e importantes da vida cotidiana”.
} 
2011, 401); observações que denotam a incompatibilidade entre as demandas de uma sociedade plural e solidária (art. $3^{\circ}$, I, CF) com sua legislação e aplicação.

Diante desse cenário de descaso com os conflitos coletivos sobre a posse urbana, não há como deixar de reconhecer a importância das inovações trazidas com o artigo 565 $\mathrm{CPC} / 15$.

O dispositivo, art. 565 do CPC/15, possui inegáveis méritos ao tratar dos litígios possessórios coletivos de forma específica, traz normatização processual procedimental própria para litígios coletivos sobre a posse, além de estender o rito especial aos pedidos de imissão de posse em ações petitórias (art. 565, § 5, CPC/15), bem como, abre a relação processual à participação dos órgãos estatais responsáveis pela política agrária e urbana (art. $\left.565, \S 4^{\circ}, \mathrm{CPC} / 15\right)$, os quais tendem a arejar o debate jurídico com argumentos multidisciplinares sobre questões urbanísticas e agrárias.

Igualmente, a necessidade de realização de audiência para mediação nos casos de posse superior ao ano e dia e nas hipóteses de demora da concessão da liminar superior a um ano (art. 565, caput e parágrafo $1^{\circ}, \mathrm{CPC} / 15$ ), pode evitar decisões açodadas que impedem o amadurecimento da convicção do juízo e inviabilizam a mobilização daqueles diretamente interessados.

Entretanto, no que diz respeito à realização da mediação, entendemos que seu potencial de promover soluções consensuais ao conflito é consideravelmente reduzido ante as disparidades econômica e jurídica entre os prováveis sujeitos da relação (ocupantes vs especuladores/poder público), assim como, o antagonismo ínsito aos interesses em jogo (moradia vs lucro imobiliário).

\section{REFERÊNCIAS}

ABREU, João Maurício Martins de. A moradia informal no banco dos réus: discurso normativo e prática judicial. Revista Direito GV, [S.1.], v. 7, n. 2, p. 391-415, jul. 2011. ISSN 2317-6172. Disponível em: <http://bibliotecadigital.fgv.br/ojs/index.php/revdireitogv/article/view/23955/22767>. Acesso em: 02 Set. 2017.

ALFONSIN, Betânia; FERNANDES, Edésio (Coord). Direito à moradia e Segurança da 
Posse no Estatuto da Cidade. Diretrizes, Instrumentos e Processos de Gestão. Belo Horizonte: Ed. Forum, 2004.

ALFONSIN, Betânia. O significado do Estatuto da Cidade para os processos de regularização fundiária no Brasil. in Regularização Fundiária Plena: referências conceituais. Rolnik, R. (org.). Brasília: Ministério das Cidades, 2007.

ANDRADE, Inácio Dias de. "A gente já nasce lutando": a desocupação do Pinheirinho, a política entre o formal e o informal. Revista de Antropologia, São Paulo, v. 56, n. 1, p. 45- 79, junho 2013. ISSN 1678-9857. Disponível em: <https://www.revistas.usp.br/ra/article/view/64460>. Acesso em: 02 sep. 2017. doi:http://dx.doi.org/10.11606/2179-0892.ra.2013.64460.

DAVIS, Mike. Planeta favela. São Paulo: Boitempo, 2006.

DIAS, Daniella Maria dos Santos. O espaço na pós-modernidade: a necessária releitura do planejamento e do ordenamento territorial nos espaços urbanos e rurais / Daniella Maria dos Santos Dias. - Rio de Janeiro: Lumen Juris, 2014

DIDIER JR, Fredie. Curso de direito processual civil: introdução ao direito processual civil, parte geral e processo do conhecimento. 19 ed. Salvador: editora juspodvim, 2017.

FARIAS, Cristiano Cahves de e ROSENVALD, Nelson. Curso de Direito Civil - Direitos Reais. Volume 5. $8^{\text {a }}$ edição. revista, ampliada e atualizada. Salvador-BA. Editora Juspodivm. 2012.

FERNANDES, Edésio. Desafios da regularização fundiária de assentamentos informais consolidados em áreas urbanas. In: Fórum de Direito Urbano e Ambiental, Belo Horizonte, v. 9, n. 49, jan. 2010. Disponível em: $<$ http://bdjur.stj.jus.br/jspui/bitstream/2011/63990/desafios_regularizacao_fundiaria_fernan de s.pdf $>$. Acesso em 03 jul. 2017.

FERNANDES, Edésio. Regularização de assentos informais: o grande desafio dos municípios, da sociedade e dos juristas brasileiros in Regularização Fundiária Plena: referências conceituais. Rolnik, R. (org.). Brasília: Ministério das Cidades, 2007.

HARVEY, David. Cidades Rebeldes: do direito à cidade à revolução urbana. São Paulo: Martins Fontes, 2014.

HOLSTON, James. Cidadania insurgente: disjunções da democracia e da modernidade no Brasil. São Paulo. Companhia das Letras, 2013.

KOWARICK, Lúcio. A espoliação urbana. Rio de Janeiro: Paz e Terra, 1993.

MAGALHÃES, Alex Ferreira. O "galo cantou", mas não foi para os moradores das favelas: problematizando a política estadual de titulação de favelas. In: Cadernos do Desenvolvimento Fluminense, Rio de Janeiro, n.1, fev. 2013. Disponível em: http://www.e-

Revista de Processo, Jurisdição e Efetividade da Justiça | e-ISSN: 2525-9814 | Salvador | v. 4 | n. 1 | p. 163 
publicacoes.uerj.br/index.php/cdf/article/view/9061/6939. Acesso em 21 de junho de 2017.

MARICATO, Ermínia. Erradicar o analfabetismo urbanístico. Entrevista à revista FASE, março de 2002. Disponível em: <http://www.fau.usp.br/depprojeto/labhab/biblioteca/textos/maricato_analfabetismourbano. pd $\mathrm{f}>$. Acesso em 15.08.2017

MARICATO, Ermínia. Cidade é luta de classes. Youtube, 11 Jan, 2016. Disponível em < https://www.youtube.com/watch?v=9R4S6ZaDniU\&t=146s $>$. Acesso em: 23 out. 17. MASTRODI, Josué; ALVES, Ederson dos Santos. A segurança jurídica da posse como pressuposto do direito fundamental à moradia / Legal security of tenure as a premise of the fundamental right to housing. Revista de Direito da Cidade, [S.1.], v. 9, n. 1, p. 27 49, jan. 2017. ISSN 2317-7721. Disponível em: <http://www.epublicacoes.uerj.br/index.php/rdc/article/view/23262 >. Acesso em: 02 mar. 2018. doi:https://doi.org/10.12957/rdc.2017.23262.

MEDINA, José Miguel Garcia. Procedimentos cautelares e especiais / José Miguel Garcia Medina, Fábio Caldas de Araújo, Fernando da Fonseca Gajardoni. - São Paulo: Editora Revista dos Tribunais, 2009.

PEREIRA, Caio Mário da Silva. Instituições de Direito Civil - Direitos Reais, $18^{\mathrm{a}}$ ed. Rio de Janeiro: Editora Forense, 2004.

ROBINSON, M. In: Vizard, P. Poverty and human rights, Sen's capability perspective explored. Oxford: Oxford University Press, 2006, p. 6. In: COSTA, Fernanda Doz. Pobreza e direitos humanos: da mera retórica às obrigações jurídicas - um estudo crítico sobre diferentes modelos conceituais. Sur, Rev. int. direitos human., São Paulo , v. 5, n. 9, p. 88- 119, Dec. 2008 . Disponível em:

$<$ http://www.scielo.br/scielo.php?script=sci_arttext\&pid=S180664452008000200006\&lng= en $\& n r m=$ iso > . Acesso em: 02/08/2017.

ROLNIK, Raquel. A construção de uma política fundiária e de planejamento urbano para o país - Avanços e desafios. In: IPEA: Políticas sociais - acompanhamento e análise. N. 12, fev. 2006. Disponível em: 〈http://ipea.gov.br/agencia/images/stories/pdfs/politicas_sociais/ensaio1_raquel12.pdf>. Acesso em 03/08/2017.

SAULE JÚNIOR, Nelson; CARDOSO, Patrícia de Menezes. O Direito à Moradia no Brasil. São Paulo: Instituto Pólis, 2005. p. 33 Disponível em: http://www.polis.org.br/uploads/911/911.pdf >. Acesso em 08 abr. 2016.

SILVA, Gerardo. ReFavela (notas sobre a definição de favela). In: Lugar Comum, n. 39, 2013. p. 37-43. Disponível em: http://uninomade.net/wpcontent/files $\mathrm{mf} / 110906130223 \mathrm{ReFavela} \% 20$ notas\%20sobre\%20a \% 20defini\%C3\%A7\%C3\%A3o\%20de\%20favela\%20-\%20\%20Gerardo\%20Silva.pdf. Acesso em: 21/07/2017.

SOUZA, Mônica Virginia de. Políticas públicas e espaço urbano desigual: favela Jardim Maravilha. In: Estudos avançados 23, 
2009. Disponível em:http://www.scielo.br/pdf/ea/v23n66/a19v2366.pdf. Acesso em 21 de junho de 2017.

TARTUCE, Fernanda. Mediação nos conflitos civis. $2^{a}$ edição. Editora Método. 2015. 